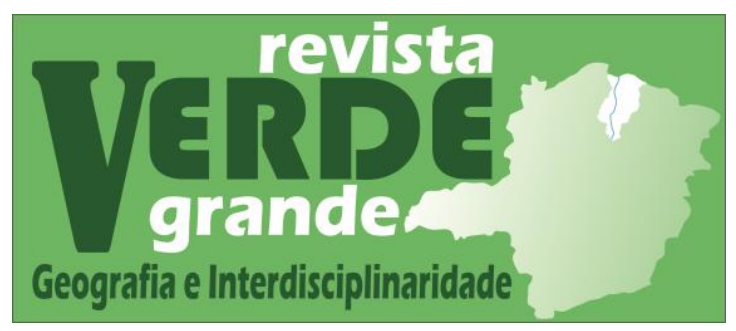

Volume 3, n‥ 2 (2021)

ISSN: 2675-2395

https://doi.org/10.46551/rvg2675239520212243248

\title{
RESENHA
}

\section{ATLAS AMBIENTAL DE MONTES CLAROS (2020)}

Glorimar da Silva Ventura ${ }^{1}$ https://orcid.org/0000-0002-5743-1878

1 Graduada em Engenharia Civil pelo Centro Universitário FIPMoc. Especialista em Estruturas Hidráulicas pela Unyleya. Mestranda em Geografia pela Universidade Estadual de Montes Claros - Unimontes. E-mail: glorimarventura@hotmail.com

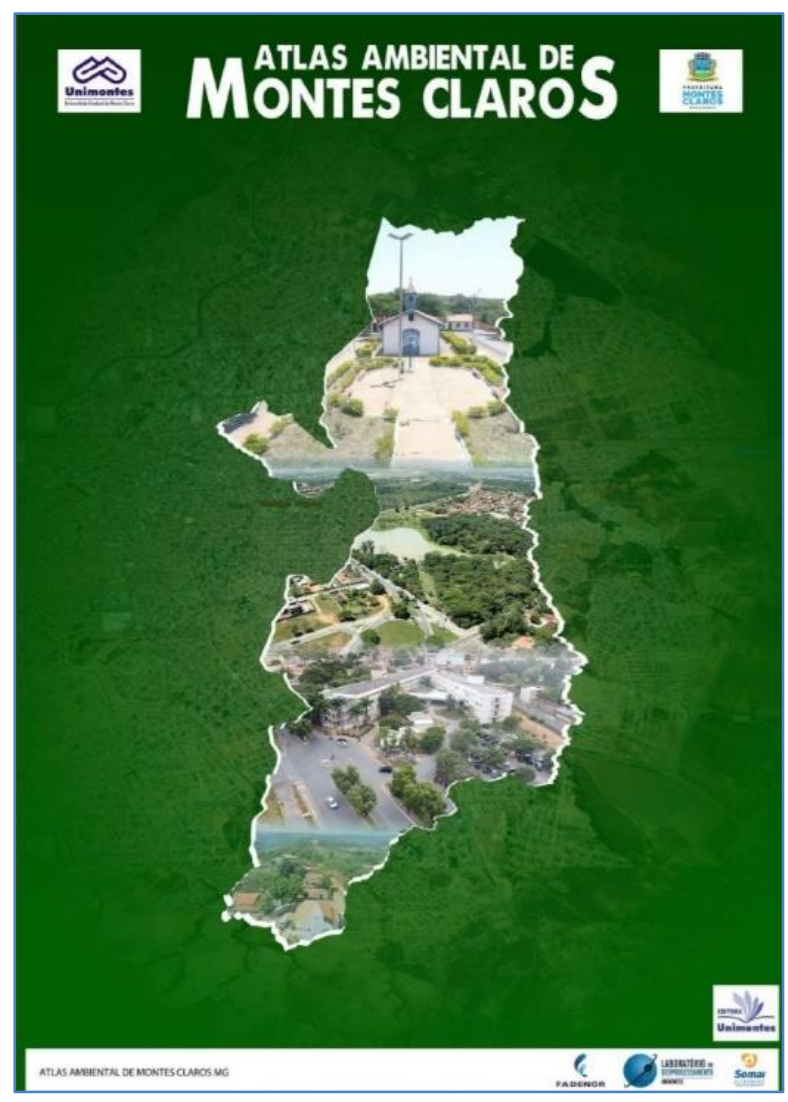

O "Atlas Ambiental de Montes Claros" (2020) é uma coletânea de mapas que caracterizam o município, com o objetivo de favorecer o processo de aprendizado no ensino básico. Organizado pelo Professor Doutor Marcos Esdras Leite o material didático foi elaborado por uma equipe de pesquisadores e bolsistas do Departamento de Geociências, da 
Universidade Estadual de Montes Claros. Entre os professores pesquisadores cita-se a Doutora Maria Ivete Soares de Almeida e os Mestres Romana de Fátima Cordeiro Leite e Manoel Reinaldo Leite.

Esse instrumento educativo foi realizado em parceria com a Prefeitura Municipal por meio das Secretarias de Meio Ambiente e Desenvolvimento Sustentável e de Educação. O envolvimento das duas secretárias municipais reforça a necessidade de formar no contexto escolar cidadãos conscientes por meio da educação ambiental. A cartografia, assim, torna-se uma ferramenta pedagógica que possibilita desenvolver a percepção dos estudantes frente à análise espacial.

Além da representação cartográfica que permite ao estudante visualizar a extensão municipal, proporcionando à construção de um olhar crítico do espaço local, aquele em que se reside, os mapas são compostos por elementos textuais. Informações que interagem com o leitor ao descrever conceitos e curiosidades, como o processo histórico de desenvolvimento municipal, os gráficos e as fotografias.

Esses elementos textuais são recursos significativos para potencializar o aprendizado, compreendendo que no ambiente escolar há diferentes maneiras de absorver os conteúdos ministrados, seja pela interpretação dos quantitativos materializados nos gráficos ou pelo exame das imagens que retratam os espaços de uso comum do município, familiarizando e despertando o interesse do estudante.

Num cenário de imersão digital vivenciado por diversos segmentos da sociedade civil, devido à pandemia do Covid19, a disponibilidade de um material gratuito auxilia os professores na composição de metodologias dinâmicas, instigando os estudantes a trocarem experiências da sua vivência cotidiana, contribuindo, assim, para um crescimento crítico do espaço geográfico habitado.

O Atlas não preenche apenas a lacuna da falta de conteúdo da localidade, mas evidencia a possibilidade de coletar dados remotamente por meio das geotecnologias, instrumentos indispensáveis para os pesquisadores nesse período pandêmico de restrição ao trabalho de campo. Ressalta-se a necessidade do deslocamento ao campo para confrontar os dados obtidos remotamente.

A estrutura do Atlas é composta por uma apresentação com coautoria do Secretário Paulo Ribeiro (in memoriam) e uma introdução e por subsequência três eixos norteadores dos mapeamentos, o primeiro intitulado "O Município", o segundo "A Cidade" e por fim o “Caderno de Atividades”. A navegação interativa do sumário permite uma localização ágil, 
basta um clique para direcionar ao mapa desejado, outro fator que cativa os estudantes habituados com as novas tecnologias.

No eixo denominado "O Município" há uma exposição de dados do Instituto Brasileiro de Geografia e Estatística (IBGE), como extensão, população urbana e rural e densidade demográfica. A diferença entre município e cidade é elucidada nesse texto introdutório. O primeiro mapa traz um recorte do município e da cidade montesclarense em relação ao panorama mundial, a redução da escala perpassa pelo Brasil, o Estado de Minas Gerais e a delimitação norte-mineira.

Os mapas posteriores apresentam a distância de Montes Claros até as cidades circunvizinhas e das capitais, ressaltando sua origem a partir dos entroncamentos rodoviários. A localização e os limites dos distritos com suas áreas são quantificados, os conceitos de distrito e vila são explicados, bem como a apresentação fotográfica de cada vila.

A visualização dos acessos ao município e dos dados de pluviosidade são acompanhados por explicações sobre os tipos de rodovias federais e de precipitações, seja frontal, convectiva ou orográfica. Assim como os índices pluviométricos a geologia, os tipos de solos, o relevo, as declividades e a hipsometria são caracterizados minunciosamente.

Considerando os racionamentos de água experimentados pelos montesclarenses nos últimos anos, divulgados pela Companhia de Saneamento de Minas Gerais - COPASA (2015), os mapas de hidrografia receberam subdivisões por bacias. Há um mapa mostrando a área drenada pelas três bacias e outros específicos, para a bacia do Rio São Lamberto, do rio Pacuí e do rio Verde Grande, onde as áreas de recarga são sinalizadas.

Convergindo com o mapeamento das áreas de preservação permanente, instrumental para proteger os recursos hídricos, a biodiversidade e o desenvolvimento humano. A preservação das nascentes é uma das medidas conservacionistas, assim cada nascente foi identificada.

Entre essas áreas de preservação o Parque Estadual da Lapa Grande ganhou destaque, sendo responsável por $40 \%$ do abastecimento público de Montes Claros. Além disso o Parque tem um valor para o turismo espeleológico, sua apresentação no Atlas estimula o interesse do leitor, sendo uma alternativa para os professores promoverem a visitação escolar, visto que muitos montesclarenses não conhecem essa unidade de conservação.

O Atlas traz uma reflexão crítica da relação sociedade-natureza por meio das análises temporais do uso e ocupação do solo no município. Ferramenta para gestão dos órgãos públicos na elaboração dos zonamentos urbanos e agroecológicos. Outras comparações são realizadas no bojo do Atlas, como a relação temperatura superficial versus cobertura vegetal. 
Um dos mapas notáveis exibe a atividade sísmica no município, a localização das falhas ou fraturas aproximadas e confirmadas, bem como a posição dos sismos. O sismo de maior magnitude na escala Richter aconteceu no ano de 2012 e gerou um alerta nos montesclarenses. Foi um período de intensas pesquisas e discussões, inclusive no ensino fundamental e médio, reiterando o auxílio da cartografia para os estudantes absorverem as temáticas emergentes.

O último mapa desse eixo retoma a discussão sobre o sensoriamento remoto por meio dos satélites, nesse caso o LANDSAT 5 é contextualizado. Por conseguinte, o eixo "A Cidade" é iniciado com parâmetros de migração recebida por Montes Claros devido seu desenvolvimento regional - expresso por meio da movimentação nos setores da educação, da saúde e das instituições financeiras. Ademais, a densidade demográfica e a distribuição dos bairros são expostas, sendo as zonas noroeste, sul e central com maior concentração populacional.

Os mapas divulgam as regiões de planejamento e os bairros da cidade. Com os dados do IBGE realiza diferentes análises ao comparar a quantidade de habitantes por região de planejamento, vinculando a população feminina e masculina por faixa etária. É possível visualizar a distribuição per capita de renda, os estabelecimentos educacionais públicos e privados, as principais avenidas e as edificações existentes. Fazendo um resgate cultural, o Atlas apresenta as edificações tombadas pelo patrimônio histórico, todas localizadas nas imediações da Praça da Matriz.

O saneamento básico recebe uma quantificação percentual por tipo de sistema, é perceptível que há regiões de planejamento que atingem a cota dos $100 \%$ para a distribuição de água e para as coletas do esgotamento sanitário e do lixo domiciliar. Entretanto, há outras regiões que não chegam aos $50 \%$ do acesso a água potável, fundamento garantido pela Política Nacional de Recursos Hídricos, instituída pela Lei no 9.433 do dia 8 de janeiro de 1997.

Além dessa questão hídrica, a expansão urbana é detalhada com mapas de hipsometria, hidrografia e áreas verdes - com destaque para o tombamento da Serra do Mel, finalizando esse segundo eixo com a evolução dessa expansão urbana entre os anos de 1970 a 2014. É evidente o potencial do "Atlas Ambiental de Montes Claros" para o ensino básico, como também para fomentar pesquisas. O professor aliado a esse material aproxima os conceitos teóricos dos livros didáticos à realidade do estudante. Criando sentido de familiaridade com a disciplina geográfica. 
Já nos anos introdutórios do ensino escolar há possibilidade de educar com os exercícios lúdicos do "Caderno de Atividades", o ato de colorir o mapa, as noções de grandeza - o maior e o menor trabalhados na educação infantil, possibilitando uma interação com as entrelinhas cartografadas, imagina-se as crianças localizando as praças, os córregos próximos a sua moradia, estimulando a criticidade enquanto cidadãos - como já pontuava Rubem Alves em 2004, o ato de ver deve ser aprendido.

O "Atlas Ambiental de Montes Claros" tem assim uma capacidade de favorecer o ensino básico, perpassando os diferentes níveis escolares, na educação infantil, no fundamental e no médio, chegando às academias universitárias para estimular as pesquisas. Como também nos projetos interdisciplinares dialogando com profissionais das áreas sociais, da saúde, da economia, das engenharias, do urbanismo e tanto outros segmentos que podem correlacionar os dados disponibilizados para delinear planos de ação sobre o contexto estudado atraindo investimentos para o município montesclarense.

\section{REFERÊNCIAS}

ALVES, Rubem. A complicada arte de ver. Revista Prosa Verso e Arte, 2004. Disponível em: https://www.revistaprosaversoearte.com/complicada-arte-de-ver-rubem-alves/. Acesso em: 11 ago. 2021.

BRASIL. Casa Civil. Subchefia para Assuntos Jurídicos. Lei $\mathbf{n}^{\mathbf{0}}$ 9.433, de 8 de janeiro de 1997. Institui a Política Nacional de Recursos Hídricos - cria o Sistema Nacional de Gerenciamento de Recursos Hídricos. Brasília, 1997. Disponível em: http://www.planalto.gov.br/ccivil_03/leis/19433.htm. Acesso em: 11 ago. 2021.

COPASA - Companhia de Saneamento de Minas Gerais. Plano de Racionamento. Seção Imprensa. 2015.2 Disponível em: https://www.copasa.com.br/wps/portal/internet/imprensa/noticias/plano-deracionamento/filter?area=/site-copasa-conteudos/internet/perfil/imprensa/noticias/plano-deracionamento/racionamento-encerrado/co-montes-claros. Acesso em: 18 ago. 2021.

LEITE, Marcos Esdras (Org.). Atlas Ambiental de Montes Claros. Montes Claros: Unimontes, 2020, 66 p. Disponível em: https://www.posgraduacao.unimontes.br/uploads/sites/7/2020/03/atlas-compactado.pdf. Acesso em: 11 ago. 2021. 
Artigo recebido em: 18 de agosto de 2021.

Artigo aceito em: 30 de agosto de 2021.

Artigo publicado em: 13 de setembro de 2021. 